\title{
A price and use comparison of generic versus originator cardiovascular medicines: a hospital study in Chongqing, China
}

Wenjie Zeng

\begin{abstract}
Background: Developed countries use generic competition to contain pharmaceutical expenditure. China, as a developing and transitional country, has not yet deemed an increase in the use of generic products as important; otherwise, much effort has been made to decrease the drug prices. This paper aims to explore dynamically the price and use comparison of generic and originator drugs in China, and estimate the potential savings of patients from switching originator drugs to generics.

Methods: A typical hospital in Chongqing, China, was selected to examine the price and use comparisons of 12 cardiovascular drugs from 2006 to 2011.

Results: The market share of the 12 generic medicines studied in this paper was 34.37\% for volume and 31.33\% for value in the second half of 2011. The price ratio of generic to originator drugs was between 0.34 and 0.98 , and the volume price index of originators to generics was 1.63 . The potential savings of patients from switching originator drugs to generics is $65 \%$.

Conclusion: The market share of the generics was lowering and the weighted mean price kept increasing in face of the strict price control. Under the background of hospitals both prescribing and dispensing medicines, China's comprehensive healthcare policy makers should take measures from supply and demand sides to promote the consumption of generic medicines.
\end{abstract}

Keywords: China, Generic medicine, Price comparison, Pharmaceutical expenditure

\section{Background}

In recent years, pharmaceutical expenditure worldwide has rapidly increased and attracted significant attention. The OECD published a recent report showing that pharmaceutical expenditure has grown by more than $50 \%$ in real terms during the last decade [1]. This increase is driven by a number of factors including stricter clinical targets, rising patient expectations, aging populations, and the continued launch of new premium-priced drugs [2]. Owing to their low price and comparable quality, generic medicines are used to enhance drug prescription efficiency and thus decrease expenditure [2-4]. In general, generic medicines tend to be $20 \%-80 \%$ cheaper than originator medicines, especially now with a

Correspondence: wenwin99@sina.com

School of Management, Chongqing Jiaotong University, No.66 Xuefu Road, Nan'an District, Chongqing 400074, China greater number imported from India (where lower production and labor costs apply) into Europe [3].

In addition, multiple supply- and demand-side reforms have been instigated in various European countries for existing drugs. Supply-side reforms include pricing reforms such as volume agreements with payback mechanisms for over budget situations and compulsory price cuts, as well as measures to obtain low prices for generics [5-11]. Demand-side measures, collated under the four Es-education, engineering, economics, and enforcement [5]-include general practitioners' incentives to prescribe generic drugs [12-14], pharmacists' use of generics in substitution for originator drugs [15-18], and consumers' attitudes to generic drugs [17-20]. These measures have resulted in some progress; e.g., there has been an increase in the use of generics in Portugal [21], generic substitution has been welcomed in Finland [17], 
and there are incentives for pharmacists' to dispense generics in France [22]. However, there is a continuing need for countries to look to the experiences of other nations to determine which measures are most appropriate for them [21].

China is also challenged by the increased financial pressure in medicine use, especially with the development of its health care reform. Since the initiation of economic reforms in 1979, the social and economic structures associated with the health sector reform have undergone significant changes. This has resulted in a decreased reliance on state funding, an increase in the cost of medical care, reduced public financing, and increased funding by user fees. In addition, individual health insurance cover in China decreased from approximately $70 \%$ in 1981 to only $20 \%$ percent in 1993 . However, this rate increased with the 2003 implementation of a new insurance scheme, namely the New Rural Cooperative Medical Insurance Scheme. In 2009 , the total medical insurance coverage rate was $93 \%$ [23]. As a proportion of total health expenditure, out-ofpocket payments rose from $20 \%$ in 1978 to $60 \%$ in 2001, and then fell to $36 \%$ in 2010. Outpatient and inpatient expenditure on pharmaceuticals from 1990 to 2010 are displayed in Table 1. In 2010, the pharmaceutical revenue of Chinese public hospitals amounted to 405.39 billion CNY (approximately US $\$ 62.37$ billion), representing $45.80 \%$ of total business revenue [24].

It must also be noted that the supply chain of generic medicines in China has its own characteristics. Owing to the changing economic system, the Chinese government reformed its pharmaceutical distribution network from a centrally controlled supply system to a market-oriented system. Thus, a competitive mechanism has been introduced into the pharmaceutical market, and acts to improve the availability of pharmaceuticals. Under this supply chain, domestic pharmaceutical production grew dramatically while numerous imported drugs began to enter into the Chinese market.

\section{Products}

Companies that wish to supply generic medicines are now asked to provide information regarding bioequiavailability before they can obtain authorization to enter the market. From 1986 to 2006, Chinese firms have independently developed only 40 categories of chemical medicines [25]. However, before 2007, the State Food and Drug Administration (SFDA) had approved 177,000 drug applications [25], meaning that most of the drug applications belonged to generics. In practice, the SFDA has adopted looser restrictions for drug registration, which gave socalled new drug licenses to minor reformulations or where only the dosage or packing of existing products were changed. In October 2007, to enhance the focus on drug safety while encouraging innovation, "Measures on the Administration of Drug Registration" were employed to improve the existing registration procedures by upgrading drug appraisal and approval standards.

\section{Manufacturers}

China currently has more than 5,000 drug manufacturing firms. Most of these are small-scale pharmaceutical businesses with a scattered geographical layout and duplicated production processes. These firms produce mainly generic drugs with little development of originator pharmaceuticals. However, China's fast growing economy and large population have meant that the pharmaceutical market has expanded tremendously, with an annual average growth of $16.1 \%$ in recent years [26]. The total output value rose from 137.1 billion RMB in 1998 to 667.9 billion RMB in 2007 [26]. After experiencing several quality issues, the government concentrated on the strict implementation of the Good Manufacturing Practice to assure product quality.

\section{Price}

Drug prices are determined by three administration authorities according to elementary indications and cost information. For state-priced products, the National Development and Reform Commission (NDRC) sets maximum retail prices (price cap); for province- or municipality-priced products, the price management department determines the retail prices; and for other products the ex-factory and retail prices are determined by the manufacturers themselves. To address the issue

Table 1 Average per capita pharmaceutical expenditures for patients in comprehensive hospitals (RMB)

\begin{tabular}{|c|c|c|c|c|c|c|}
\hline Year & $\begin{array}{l}\text { Average medical charges } \\
\text { for per outpatient }\end{array}$ & Medicine fee & Proportion $\%$ & $\begin{array}{c}\text { Average medical } \\
\text { charges for inpatient }\end{array}$ & Medicine fee & Proportion $\%$ \\
\hline 1990 & 10.9 & 7.4 & 67.9 & 473.3 & 260.6 & 55.1 \\
\hline 1995 & 39.9 & 25.6 & 64.2 & 1667.8 & 880.3 & 52.8 \\
\hline 2000 & 85.8 & 50.3 & 58.6 & 3083.7 & 1421.9 & 46.1 \\
\hline 2005 & 126.9 & 66 & 52.1 & 4661.5 & 2045.6 & 43.9 \\
\hline 2008 & 146.5 & 74 & 50.5 & 5463.8 & 2400.4 & 43.9 \\
\hline 2009 & 159.5 & 81.2 & 50.9 & 5951.8 & 2619.8 & 44 \\
\hline 2010 & 173.8 & 88.1 & 50.7 & 6525.6 & 2834.4 & 43.4 \\
\hline
\end{tabular}


of "unusually high" prices for common use or expensive medicines (e.g., antibiotics, cardiovascular drugs, and anticancer drugs) the NDRC implemented 28 price adjustments between 1997 and 2011 [27]. Before entering catalogs for hospital procurement, the above medicines are subject to tenders for provision in each province and municipality, and procurement prices for hospitals are then determined. For cardiovascular drugs, the price was changed four times between 2006 to 2011 in Chongqing Urban District: two changes were invitations for tenders in March 2006 and April 2011, and two were attributed an NDRC adjustment of maximum retail prices in January 2007 and March 2011.

\section{Market}

By the end of 2007 China had 13,000 wholesale pharmaceutical enterprises, 341,000 retail pharmaceutical enterprises and chain store enterprises, and 554,000 rural drug supply outlets [26]. These sales agents use sales commissions, tourism, kickbacks, and gifts to hospital managers and/or doctors who purchase or prescribe their products. The commercial promotional activities and profits of multi-layered distribution is a substantial component of the total costs of pharmaceuticals.

Data from the Datamonitor Group offer an insight into China's generic market. The Chinese generics market grew by $11.3 \%$ in 2010 to reach a value of US $\$ 19,645.3$ million. The compound annual growth rate of the market in the period 2006-2010 was $16.4 \%$. The Chinese generics market shrank by $0.2 \%$ in 2010 to reach a volume of $95.3 \%$ of total pharmaceutical volume. The compound annual rate of change of the market in the period $2006-2010$ was $-0.2 \%$.

\section{Physicians}

In China, hospital physicians prescribe and dispense drugs, which means that every hospital has had its own pharmacy, dispensing more than $80 \%$ of China's total medicine consumption; the remaining $20 \%$ of medicine is distributed by community drug stores [26]. The current reimbursement system used in pharmaceutical expenditure in Chinese hospitals induces dispensing doctors (DDs) to overprescribe drugs to patients and to prescribe drugs that produce the greatest profit for themselves [28]. Furthermore, the profit markups that DDs might receive from drug prescriptions are determined by the price of the medicines. In a comparative study, Lim expressed that DDs prescribed more medicines to patients than their non-dispensing counterparts [29]. Research from other regions in Southeast Asia also reinforced the notion that physicians could profit by both prescribing and dispensing drugs, and that more originator drugs were prescribed than generic drugs [30].

The "Prescription Management Ordinance" promulgated by the Chinese government in 2007 specified that prescriptions should be written using generic names or INN (international nonproprietary names). However, this ordinance has done little to increase the use of generics. For example, prescription sheets indicate brand name or manufacturer name, or these are already selected in the hospital's electronic information system. Although prescription sheets can be filled in community pharmacies, and generic substitution for originator prescriptions is common in developed countries, such practices are rare in Chinese hospitals and community pharmacies.

Owing to the high number of pharmaceutical factories in China and low-priced products, it is hoped that the use of generics will eventually increase. However, the generic market in China has its own characteristics. In this paper, a dynamic perspective is taken with principal cardiovascular drugs to reveal the current situation concerning generic use, market share, and price comparisons. This will provide us with the fundamental information required to explore potential measures to promote the use of generic drugs in China.

\section{Methods}

\section{Data source}

As stated above, under the current situation of no SPD, $80 \%$ of drugs are sold in hospitals, and drug prices for hospital procurement are determined by a tender process in each province and municipality. Price variations for hospital drugs exist in each district, even in the same city, and these prices are constantly changing. Therefore, we chose data from one restricted district, i.e., Chongqing, to compare price and use evolutions.

Chongqing is a municipality directly under China's central government. It is located in Southwest China with a total population of 23 million people. The leading therapeutic drug classes consumed in its hospitals were identified as anti-infective agents, and medicines for cardiovascular, digestive, and nervous systems [31]. Because of frequent price fluctuations, product variations, policy changes, and specific prescribing patterns, anti-infective agents were not suitable for this research. In contrast, cardiovascular drugs involve many pharmaceuticals for chronic diseases, and their long-term usage with relatively stable products made them suitable for this study, and in the study period the drug price was the most important factors affecting the utilization structure. Other researchers have also studied this kind of medicine $[7,32]$. We chose a typical hospital in which to conduct our investigation, i.e., a hospital affiliated to the Third Military Medical University, which is one of the largest hospitals in Southwest China. It is also a typical health provider because of the services it provides to the public.

The dataset was obtained from the magazine company of China Pharmacy (an authoritative Chinese Journal). 
The magazine company is located in Chongqing, which makes it easy for it to collect detailed information from the larger hospitals in Southwest China. The dataset contains all individual delivery information including product name, purchase date, dosage form, specification, manufacturer, unit price, and purchase volume, which was collated from the hospital's procurement records.

\section{Selection of generic and originator medicines}

In this research, originator medicines are referred to as products once possessing intellectual property, and almost all these medicines are global products provided by international pharmaceutical enterprises including Bayer, Pfizer, and AstraZeneca et al. Generic drugs are domestic chemical products produced by enterprises with local investments, and most of the medicines are in strong competition with a number of manufacturers.

A set of different drug classes (each class containing one originator and one or more generic drugs of the same chemical entity) were chosen to compare their market share and price evolution. Based on our dataset and other reports, the three most prescribed drug groups in cardiovascular medicines were chosen for this study, including calcium channel blockers with mainly vascular effects, sartans, and statins [7,32]. Of the 19 matched products, 12 products were used in this study. Some products with relatively high usage rates were not used (such as Fluvastatin, Pitavastatin, and Losartan) because they lacked data from domestic generic products.

\section{Price calculation, comparison}

Ordinarily, three kinds of drug prices are used in price comparison research, i.e., ex-manufacturer price, wholesale price, and retail price. The retail price policy of the hospital pharmacy has been adjusted several times, and the markup has decreased from 50\% to approximately $15 \%$ (in some districts it has been reduced to zero in 2012). In this paper, the hospital's procurement price was adopted to avoid eventual retail price discrepancies. The Chinese currency renminbi (RMB) "yuan" is used to determine the price and value, and the exchange rate was RMB 6.12 to US\$1.00 on September 12, 2013.

We employed defined daily doses (DDDs) as a standard unit of measurement according to the World Health Organization definitions of these 12 products [33,34], and used the price per DDD (DDDc) to empirically measure the procurement price set. That is, we transformed the directly observable procurement price $\left(P_{\mathrm{p}}\right)$ into DDDc using a equation: $\mathrm{DDDc}=\left(P_{\mathrm{p}} / \mathrm{Q}\right) \times \mathrm{DDD}$, where $Q$ indicates the dosage unit per package (or strength of product).

The prices of the individual and overall 12 products were assayed by adopting a weighted mean price, which were calculated by dividing market value by market volume. For the price comparison of generic and originator drugs in 2011, the price index $\left(P_{\text {volume }}\right)$ was calculated according to the weighted volume of the procurement $\left(\omega_{\mathrm{i}}\right)$.

$$
\begin{aligned}
& \text { Pvolume }=\sum_{i=1}^{n} \frac{\text { Poriginators' }^{\prime}}{\text { Pgenerics }} \times \omega_{i} \\
& \omega_{i}=\frac{\text { Volume }_{i}}{\sum_{i=1}^{n} \text { Volume }_{i}}
\end{aligned}
$$

where Volume $_{i}$ indicates the total volume (DDDs) of a medicine, and poriginator or penerics indicates the weighted mean price (DDDc, $P_{w}$ ).

We took six months as the analysis period, because one year is too long to express the volume change and one quarter is too short to remove possible anomalies. And we used " $1 \mathrm{H}$ " to represent the first half year and " $2 \mathrm{H}$ " for the second half year.

\section{Results}

\section{Market share of generic and originator drugs}

The market share for volume of generic drugs decreased from approximately 50\% in the first half year of 2006 to $34.37 \%$ in the second half year of 2011, and that of originator drugs increased to $65.63 \%$ (Figure 1). A continuous decrease in generics market share could be observed in the early years until it reached its stable platform in the first half year of 2008 and maintained narrow fluctuations in the following years.

The evolution of the market share for value was more complicated. The value share of generic drugs also steadily decreased in the early years until it reached its valley floor $(23.52 \%)$ in the first half of 2008 , and then it increased slowly to $31.33 \%$.

\section{Price and use evolution}

The overall weighted mean price (DDDc) and total volume (DDDs) of 12 cardiovascular medicines from 2006 to 2011 were calculated and presented in Figure 2. The half-year total volume of generic and originator drugs increased continuously, but the increase rate of originator drugs was much higher than that of the generics. The weighted mean price of generics was also in a rising channel, in contrast with the originator drugs, which attributed to the sharp price decline of Simvastatin by its manufacturer Merck Co. to compete for market share in the end of 2009.

\section{Price comparison and potential savings}

Because some of the products were not purchased, especially generic drugs in the early study years, we employed the latest data (2011) to compare the price of generic and originator medicines.

We used the proportion of the individual volume in the total volume as the weighted index, and calculated 
the price comparison index. The overall prices of the 12 generic and originator drugs are displayed as DDDc in Table 2. The ratios of DDDc of generic to originator medicines ranged from 0.34 to 0.98 . The volume index of originator to generics was 1.63. Thus, the price of originator drugs is $63 \%$ higher than generics.

For all 12 brand-name drugs, generic drugs were available in the identical form with lower prices. We could estimate the potential savings from more consistent use of generic drugs for each individual medication in the following way:

$$
\begin{aligned}
& \text { Potential savings } s_{\text {originator }} \\
& \quad=\Sigma\left[D D D s_{\text {originator }} \times\left(D D D c_{\text {originator }}-D D D c_{\text {generics }}\right)\right]
\end{aligned}
$$

The potential savings from general substitution of these 12 originator drugs in 2011 is 4.19 million RMB, with a proportion of $66 \%$ for originator utilization.

\section{Principal generic products}

Among the generic drugs with the highest DDDc (with the exception of Pravastatin Sodium launched late in 2009), two products, i.e., Amlodipine and Atorvastatin Calcium, showed significant increase of use in the study period, especially in recent years (see Figure 3). The market shares of these two products were $43.01 \%$ and $30.80 \%$ for general value in 2011, which were much higher than for other products. This reveals an extremely abnormal phenomenon in generic drug use.

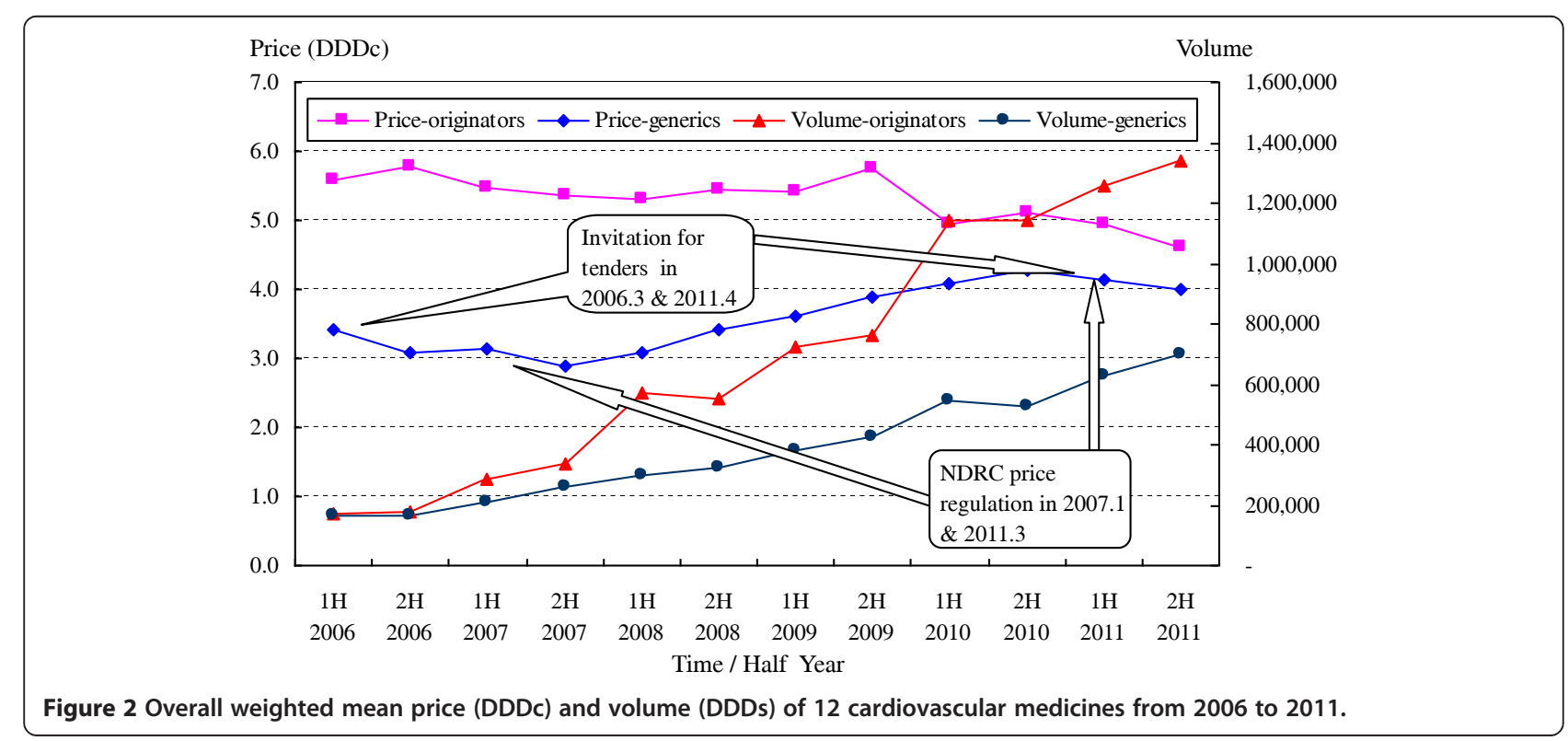


Table 2 Price comparisons of 12 generic and originator drugs in 2011 (DDDc, RMB)

\begin{tabular}{|c|c|c|c|c|c|}
\hline Medicine & $\begin{array}{l}\text { Prices of } \\
\text { generics }\end{array}$ & $\begin{array}{c}\text { Number of local } \\
\text { manufacturers }\end{array}$ & $\begin{array}{c}\text { Prices of } \\
\text { originators }\end{array}$ & $\begin{array}{c}\text { Global } \\
\text { manufacturer }\end{array}$ & $\begin{array}{c}\text { Generics to } \\
\text { originators ratio }\end{array}$ \\
\hline Nifedipine & 1.57 & 4 & 4.47 & Bayer & 0.35 \\
\hline Amlodipine & 4.68 & 4 & 4.78 & Pfizer & 0.98 \\
\hline Felodipine & 1.61 & 1 & 3.27 & AstraZeneca & 0.49 \\
\hline Lacidipine & 1.27 & 1 & 3.68 & GlaxosmithKline & 0.34 \\
\hline Simvastatin & 2.94 & 1 & 3.97 & Merck & 0.74 \\
\hline Pravastatin Sodium & 5.80 & 1 & 7.04 & Sankyo & 0.82 \\
\hline Atorvastatin Calcium & 7.73 & 2 & 9.22 & Pfizer & 0.84 \\
\hline Irbesartan & 3.21 & 1 & 4.47 & Sanofi-Synthelabo & 0.72 \\
\hline Irbesartan and Hydrochlorothiazide & 3.19 & 1 & 4.47 & Sanofi-Synthelabo & 0.71 \\
\hline Losartan Potassium and Hydrochlorothiazide & 3.90 & 1 & 5.89 & Merck & 0.66 \\
\hline Valsartan & 2.41 & 1 & 5.76 & Novartis & 0.42 \\
\hline Telmisartan & 1.74 & 1 & 2.44 & Boehringer Ingelheim & 0.71 \\
\hline
\end{tabular}

Otherwise, the discrimination in the market share of originator drugs was much lower, ranging from $4.10 \%$ to $17.82 \%$ in value, with the only exception of Lacidipine at just $0.73 \%$.

\section{Discussion}

The results in this paper reveal the current situation regarding 12 generic cardiovascular medicines in a hospital in China:

- -Total volume: There was an obvious increase in the use of both generic and originator medicines. In the second half of 2011, the volume of prescribed generics was 4.27 times that in the beginning of the study period, and 7.72 for originators.
- -Market share: In the second half of 2011, the market share of the 12 generic medicines decreased to $34.37 \%$ for volume (DDDs) and 31.33\% for value, compared with $48.64 \%$ (volume) and $36.65 \%$ (value) at the beginning of the study period.

- -Price comparison: The price ratios of generic to originator drugs were between 0.34 and 0.98 , and the volume price index of originator to generics was 1.63 . Thus, the price of originator drugs is $63 \%$ higher than generics for volume. The weighted mean price of generics shows an increasing trend.

- -Special products: Two principal generic products, i.e., amlodipine and atorvastatin calcium, occupied $43.01 \%$ and $30.80 \%$ of the market share in generic value, respectively. These shares are substantially

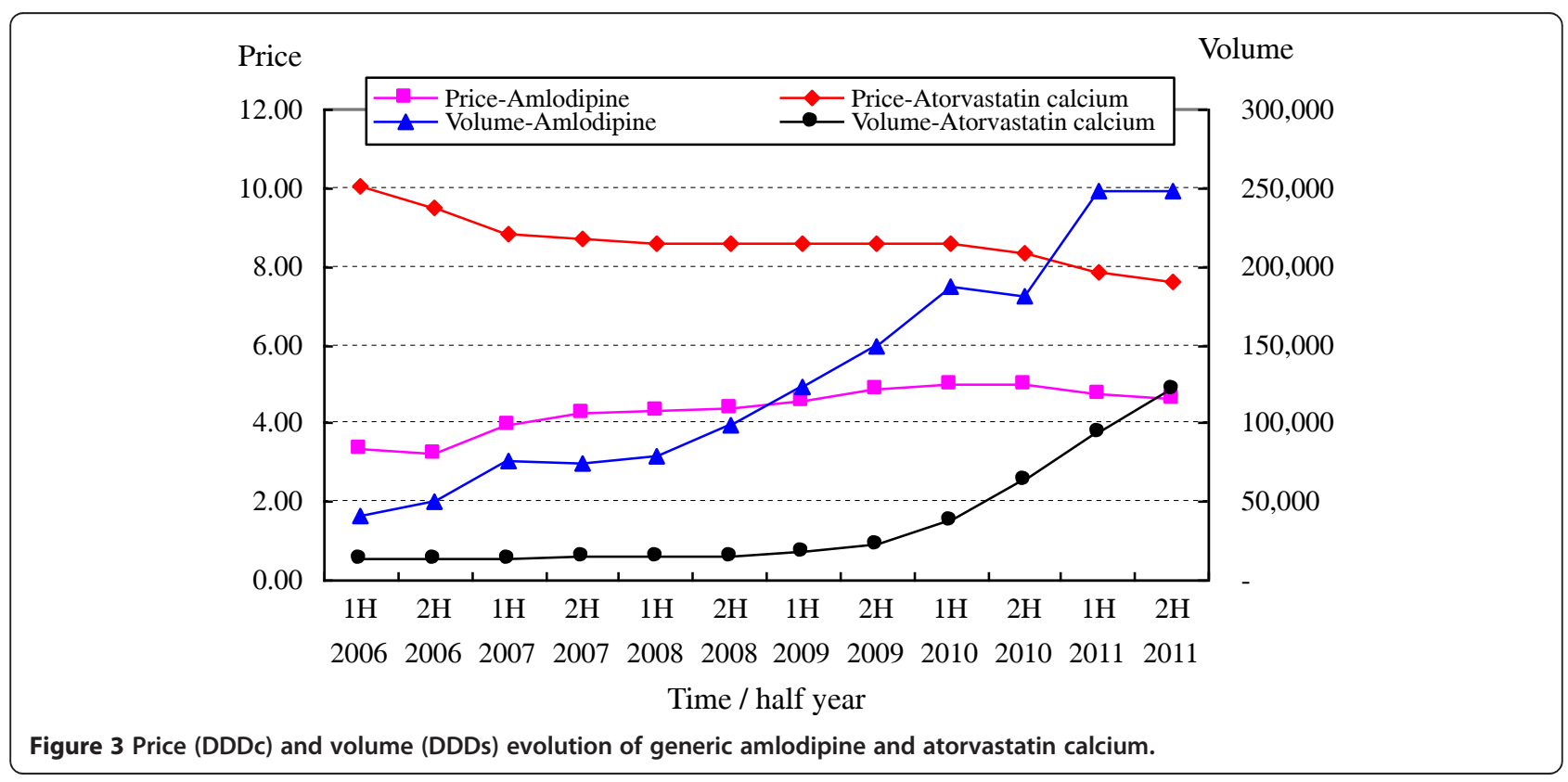


higher than those enjoyed by other generic products.

As a general trend, pharmaceutical consumption in China has experienced a significant increase in recent years. The increase in cardiovascular drug consumption can be attributed to a number of reasons, including urbanization, an aging of population accompanied by an increase of chronic diseases, the expansion of the scope of medical insurance, and improvements in living standards. Using the experience of other countries for reference, generic substitution can decrease pharmaceutical expenditure, with a potential saving of $66 \%$ for patients by switching from originator to generic drugs. This result is similar to the results from a study on four generic medicines in China (which showed a 65\% saving) [35], and a further study that found a $60 \%$ reduction in costs where patients used generic substitutions in 17 middle-income countries [36].

However, the increasing trend of the weighted mean price of generics, the lowering market share of generics, and the fact that just two principal generic products enjoy a substantially higher market share, can be largely explained by changes in the consumption structure, suggesting that more higher priced drugs were prescribed than cheaper ones by hospital physicians (this can be observed in Figures 1 and 2 by contrasting the evolution of the volume and value market share of generic and originator drugs). For example, the abnormal phenomenon in generic drug use of two principal generic products might be attributed to the relatively higher DDDs, which would bring greater economic interests to the whole supply chain from the prescribing and dispensing of these two drugs.

We can learn two lessons from these results. The first concerns the current state of the Chinese health sector, where hospitals prescribe and dispense drugs. From another point of view, this paper also reveals the attitudes of DDs to generic medicines, because most drugs are consumed according to doctors' prescriptions. Owing to the financial incentives of DDs as incompetent agents and nontransparent price and quality information for patients, DDs may prescribe more expensive drugs than needed.

The second implication regards the drug price policy employed in China in recent years. Although the direct price cut or invitation for tenders can affect drug costs in the short term, the pharmaceutical supply chain adjusts the product structure and increases the weighted mean price in the long term. In contrast, the average price of medicines has dropped in recent years by 43.18\% in European countries with high generic market shares and by $21.56 \%$ in low market share countries [3].

Generic competition, in general, changes the market and decreases the price of medicines. The creation of a sustainable generic pharmaceutical market requires active regulatory and marketing measures at all levels including incentives for manufactures, physicians, and dispensers $[7,37]$. For China's comprehensive healthcare policy makers, there is a long way to go before an appropriate system to promote the consumption of generic medicines can be established, especially under the background of hospitals both prescribing and dispensing medicines. Potential measures should stem from supply and demand sides, including a corresponding policy for greater transparency in the pricing of generics, restrictive prescription regulations for physicians, health education to ensure the greater acceptance of generics by patients, and a reimbursement system for the prescription of generics $[38,39]$.

This research is subject to some limitations, for example, the data collection was from just one region, one hospital, and one indication; this occurred because data from community drugstores are not easy to collect. The market share of generics may not represent all hospitals, but the price ratio of originator to generics did reveal the situation in Chongqing hospitals, and thus does show the current situation in Chinese hospitals. In addition, the effect of traditional Chinese medicine was not included in this study, which might have a substantial effect on the usage structure of chemical products. Furthermore, some new drugs were also launched during the study period from 2006 to 2011; these were few and any effect was not apparent.

\section{Conclusions}

This study is the first dynamic exploration of the price and use comparison of generic and originator drugs in a Chinese hospital. The market share of the generics was lowering and the weighted mean price kept increasing in face of the strict price control. And two principal generic products with relatively high DDDc occupied most of the market shares in generic value, suggesting an extremely abnormal phenomenon in general utilization. Under the background of hospitals both prescribing and dispensing medicines, China's comprehensive healthcare policy makers should take measures from supply and demand sides to promote the consumption of generic medicines.

\section{Competing interests}

The author declare that they have no competing interests.

\section{Acknowledgment}

I thank the publishing company of the Journal of China Pharmacy for providing us with the dataset used in this study.

Received: 1 March 2013 Accepted: 1 October 2013

Published: 5 October 2013

\section{References}

1. OECD: Health at a glance 2011. http://www.oecd.org/health/health-systems/ health-at-a-glance.htm

2. Godman B, Abuelkhair M, Vitry A, Abdu S, Bennie M, Bishop I, Fahmy S, Garuoliene K, Herholz H, Martin A, Malmstrom RE, Jan S, Schwabe U, Sermet C, Skiold P, Voncina L, Gustaff son LL: Payers endorse generics to enhance 
prescribing efficiency; impact and future implications, a case history approach. GABI 2012, 1:69-83.

3. Dylst $P$, Simoens $S$ : Does the market share of generic medicines influence the price level? A european analysis. Pharmacoeconomics 2011, 29:875-882

4. Perry G: The European generic pharmaceutical market in review: 2006 and beyond. J Generic Med 2006, 4:4-14.

5. van Woerkom M, Piepenbrink H, Godman B, de Metz J, Stephen C, Bennie $M$, Eimers $M$, Gustafsson LL: Ongoing measures to enhance the efficiency of prescribing of PPIs and statins in the Netherlands; influence and future implications. J Comp Effectiveness Res 2012, 1:527-538.

6. Regan TL: Generic entry, price competition, and market segmentation in the prescription drug market. Int J Ind Organ 2008, 26:930-948.

7. Manova MM, Stoimenova A, Clerfeuille F, Petrova Gl: Impact of generic competition on market share and prices of cardiovascular medicines on the Bulgarian pharmaceutical market. J Public Health 2011, 19:91-100.

8. Lexchin J: The effect of generic competition on the price of brand-name drugs. Health Policy 2004, 68:47-54.

9. Puig-Junoy J: Impact of European pharmaceutical price regulation on generic price competition: a review. Pharmacoeconomics 2010, 28:649-663.

10. Simoens S: Developing the Japanese generic medicines market: what can we learn from Europe? J Generic Med 2009, 6:129-135.

11. Dalen DM, Strom S, Haabeth T: Price regulation and generic competition in the pharmaceutical market. Eur J Health Econ 2006, 7:208-214.

12. Chu C, Rudant E, Bonvalet $M$, Agostini $H$, Cavalié $P$, Bonhomme-Faivre L, Frenkiel J, Taillandier J, Boissonnas A, Vittecog D, Wyplosz B: Generic drug prescriptions following hospital discharge: a prospective study in France. Eur J Intern Med 2011, 22:45-49.

13. Rodríguez-Calvilloa JA, Lanaa A, Cuetoa A, Markhamb WA, López ML: Psychosocial factors associated with the prescription of generic drugs. Health Policy 2011, 101:178-184.

14. Paraponaris $A$, Verge $P$, Desquins $B$, Villani $P$, Bouvenot $G$, Rochaix $L$, Gourheux JC, Moatti JP, Paca MG: Delivering generics without regulatory incentives? Empirical evidence from French general practitioners about willingness to prescribe international non-proprietary names. Health Policy 2004, 70:23-32.

15. Pechlivanoglou P, Veen WJ, Bos JH, Postma MJ: Analyzing generic and originator substitution patterns in the Netherlands using prescription data. BMC Health Serv Res 2011, 11:89.

16. Babar Z, Grover P, Stewart J, Hogg M, Short L, Seo HG, Rew A: Evaluating pharmacists' views, knowledge, and perception regarding generic medicines in New Zealand. Res Soc Adm Pharm 2011, 7:294-305.

17. Heikkila R, Ma"ntyselka $P$, Ahonen R: Do people regard cheaper medicines effective? Population survey on public opinion of generic substitution in Finland. Pharmacoepidemiol Drug Saf 2011, 20:185-191.

18. Chong CP, March G, Clark A, Gilbert A, Hassali MA, Bahari MB: A nationwide study on generic medicines substitution practices of Australian community pharmacists and patient acceptance. Health Policy 2011, 99:139-148.

19. Quintal C, Mendes P: Underuse of generic medicines in Portugal: an empirical study on the perceptions and attitudes of patients and pharmacists. Health Policy 2012, 104:61-68.

20. Decollogny A, Eggli Y, Halfon P, Lufkin TM: Determinants of generic drug substitution in Switzerland. BMC Health Serv Res 2011, 11:17.

21. Godman B, Bennie M, Baumgärtel C, Sović-Brkičić L, Burkhardt T, Fürst J, Garuoliene K, Gomes M, Markovic-Pekovic V, Martin A, Sermet C, Skiold P, van Woerkom M, Voncina L, Gustafsson LL: Essential to increase the use of generics in Europe to maintain comprehensive healthcare? Farmeconomia: Health Econ Ther Pathways 2012, 13(Suppl 3):5-20.

22. Sermet C, Andrieu V, Godman B, Ganse EV, Haycox A, Reynier JP: Ongoing pharmaceutical reforms in France; implications for key stakeholder groups. Appl Health Econ Health Policy 2010, 8:7-24.

23. Ngorsuraches S, Meng W, Kim BY, Kulsomboon V: Drug reimbursement decision-making in Thailand, China, and South Korea. Value Health 2012, 15:120-125.

24. National Health and Family Planning Commission of China: China Health Statistics Annuals 2011. http://wsb.moh.gov.cn/htmlfiles/zwgkzt/ptjnj/ year2011/index2011.html.

25. Sun Q, Santoro MA, Meng Q, Liu C, Eggleston K: Pharmaceutical policy in China. Health Aff 2008, 27:1042-1050.

26. Yu X, Li C, Shi Y, Yu M: Pharmaceutical supply chain in China: current issues and implications for health system reform. Health Policy 2010, 97:8-15.
27. Tao T, Xu C, Hu M, Liao W, Jiang X: Analysis of Chinese pharmaceutical price policy from 1997 to 2011. Chin J Health Policy 2011, 4:46-52.

28. Chen Y, Schweitzer SO: Issues in drug pricing, reimbursement, and access in China with references to other Asia-Pacific region. Value Health 2008, 11:124-129.

29. Lim D, Emery J, Lewis J, Sunderland VB: A systematic review of the literature comparing the practices of dispensing and non-dispensing doctors. Health Policy 2009, 92:1-9.

30. Liu YM, Yang YHK, Hsieh CR: Financial incentives and physicians' prescription decisions on the choice between brand-name and generic drugs: Evidence from Taiwan. J Health Econ 2009, 28:341-349.

31. Jin SR, Hu L, Du L, Huang K: Analysis of drug use in 29 hospitals of Chongqing area from 2008 to 2010. China Pharm 2012, 23:872-876.

32. Chen $C L$, Chen $L$, Yang WC: The influences of Taiwan's generic grouping price policy on drug prices and expenditures: evidence from analysing the consumption of the three most-used classes of cardiovascular drugs. BMC Public Health 2008, 8:118.

33. World Health Organization: Guidelines for ATC classification and DDD assignment. Oslo: WHO Collaborating Centre for Drug Statistics Methodology. www.whocc.no.

34. World Health Organization, WHO International Working Group for Drug Statistics Methodology, WHO Collaborating Centre for Drug Statistics Methodology, WHO Collaborating Centre for Drug Utilization Research and Clinical Pharmacological Services: Introduction to drug utilization research. http://apps.who.int/iris/bitstream/10665/42627/1/924156234X.pdf.

35. Cameron A, Laing R: Cost savings of switching private sector consumption from originator brand medicines to generic equivalents. In World Health Report (2010) background paper, 35. Geneva: World Health Organization; 2010. http://www.who.int/healthsystems/topics/financing/ healthreport/35MedicineCostSavings.pdf.

36. Mathauer I, Carrin G: The role of institutional design and organizational practice for health financing performance and universal coverage. In World Health Report (2010) background paper, 36. Geneva: World Health Organization; 2010. http://www.who.int/healthsystems/topics/financing/ healthreport/36Institutional.pdf.

37. Dylst P, Vulto A, Godman B, Simoens S: Generic medicines: solutions for a sustainable drug market? Appl Health Econ Health Policy 2013. http://dx.doi. org/10.1007/s40258-013-0043-z

38. Bennie M, Godman B, Bishop I, Campbel S: Multiple initiatives continue to enhance the prescribing efficiency for the proton pump inhibitors and statins in Scotland. Expert Rev Pharmacoecon Outcomes Res 2012, 12:125-130.

39. Godman B, Sakshaug S, Berg C, Wettermark B, Haycox A: Combination of prescribing restrictions and policies to engineer low prices to reduce reimbursement costs. Expert Rev Pharmacoecon Outcomes Res 2011, 11:121-129.

doi:10.1186/1472-6963-13-390

Cite this article as: Zeng: A price and use comparison of generic versus originator cardiovascular medicines: a hospital study in Chongqing, China. BMC Health Services Research 2013 13:390.

\section{Submit your next manuscript to BioMed Central and take full advantage of:}

- Convenient online submission

- Thorough peer review

- No space constraints or color figure charges

- Immediate publication on acceptance

- Inclusion in PubMed, CAS, Scopus and Google Scholar

- Research which is freely available for redistribution 